\title{
INSTITUTIONAL APPROACHES TO THE DEVELOPMENT OF SOLID WASTE TREATMENT AND ITS STAFFING IN THE RUSSIAN FEDERATION
}

\author{
Vasiliy Rud' \\ Saint-Petersburg Polytechnical University, \\ 29, Polytekhnicheskaya st., St.-Petersburg, 195251,Russia, \\ e-mail: rudvas.spb@gmail.com, \\ Serguey Trukhachev \\ Lomonosov Moscow State University, Faculty of Economics, Russia, 119991, Moscow, \\ GSP-1, 1-46 Leninskiye Gory
}

\begin{abstract}
Research , the results of which will be discussed in the present report were obtained in the framework of the Commission under the President of the Russian Federation for Modernization and Technological Development of Russia's Economy.

Key issues affecting the management of the flow of all types of waste in Russia are:

- A huge number of unsorted household waste and unprocessed

- Extremely high yield landfill business and its criminal

- Lack of waste treatment business

- Possibility of selling the energy received from the recycling can not be considered as an incentive for the development of business

- Building regulations do not provide for the installation of systems for separate collection of household waste
\end{abstract}

Public services and private investors are not able to effectively solve the problem of eliminating the effects of pollution of waste production and consumption with the formation of an efficient, costeffective and environmentally sound waste management industry.

It is necessary to pay more attention to not direct support projects on waste recycling, and introduce restrictive measures for the development of businesses not harmless to the garbage.

We need to develop a "roadmap" of joint actions of government and business to create a national market for emissions trading of greenhouse gas emissions on the basis of voluntary commitments by companies to reduce them.

As a result of the work done has been formulated for a number of assignments signed by the President of the Russian Federation .

\section{KEYWORDS}

municipal solid management; public-private partnership; institutionalism; project management. 


\section{INTRODUCTION}

Over the past 5 years, the volume of waste in Russia increased by 1.5 times and amounted to more than 3.5 mlrd.tonnes. In the foreseeable future, to reduce the formation of prerequisites of waste there, and then the problem will only get worse . The situation in Russia in the field of waste management poses a direct threat to environ - mental protection , and public health. Unsustainable use of natural resources, and also causes the appearance of economic damage caused by the excretion of economic turnover is irretrievably lost valuable material resources. Re-use of secondary material resources from the waste stream , reduces tension a number of environmental , economic and social problems . Poor state of the waste management system has a negative impact in the economic, social and environmental spheres that case tains the basis for the development of organizational and economic measures to reorganize the system for solid waste management . Recycling of municipal solid waste in Russia is in its infancy, but has significant prospects. In Europe, recycling of MSW is in the competence of small and medium entrepreneurship. In Russia, the business associated with the collection, preparation and processing of waste is not popular . This is due to the specifics of the waste as a commodity and the object of sale , as entrepreneurs often have to work with very polluted unsorted raw material , a significant portion of which relates to the resources for which there is no possibility of technological processing.

\section{INSTITUTIONAL APPROACHES TO THE DEVELOPMENT OF SOLID WASTE TREATMENT}

Institutional approaches to the develop of solid waste treatment in Russia discussed in the working group of the Commission under the President of the Russian Federation for Modernization and Technological Development of Russia's Economy. The imp of such work was to present Presidents Draft orders for the government and ministries of Russia.

To take in account that basic parameters of any liquid or viscous medium e.g to stimulate the development of domestic entrepreneurs need to waste recyclers solve a number of problems that hinder the development of this sphere of activity.

These problems primarily may include:

- Imperfection of the legal framework in waste management ;

- Underdeveloped infrastructure management system of waste;

- Absence of a system of selective collection of solid waste ;

- The lack of economic incentives to involve waste in repeated economic circulation ;

- Ineffectiveness of the waste management system at the local level ;

Certain problems can not be solved without an effective system of interaction of public authorities, business entities and population. The experience of the advanced countries in the field of management Waste can be adapted to the conditions of the Russian reality.

The experience of developed countries shows that to improve competitiveness of the sphere of municipal solid waste Dov must develop attractive for investors investment policy, which should be developed in the context of the overall investment policy city as its section . . 


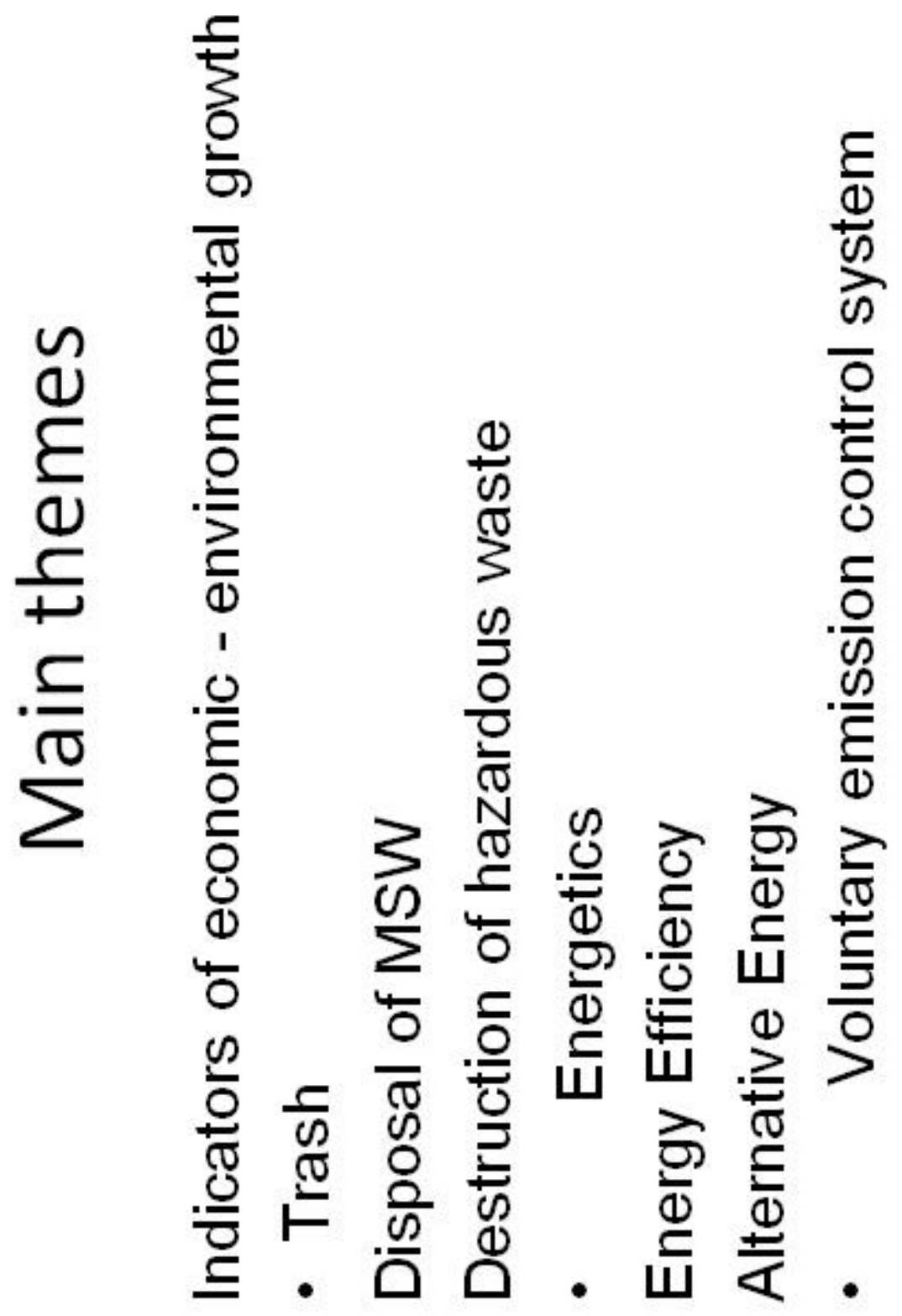




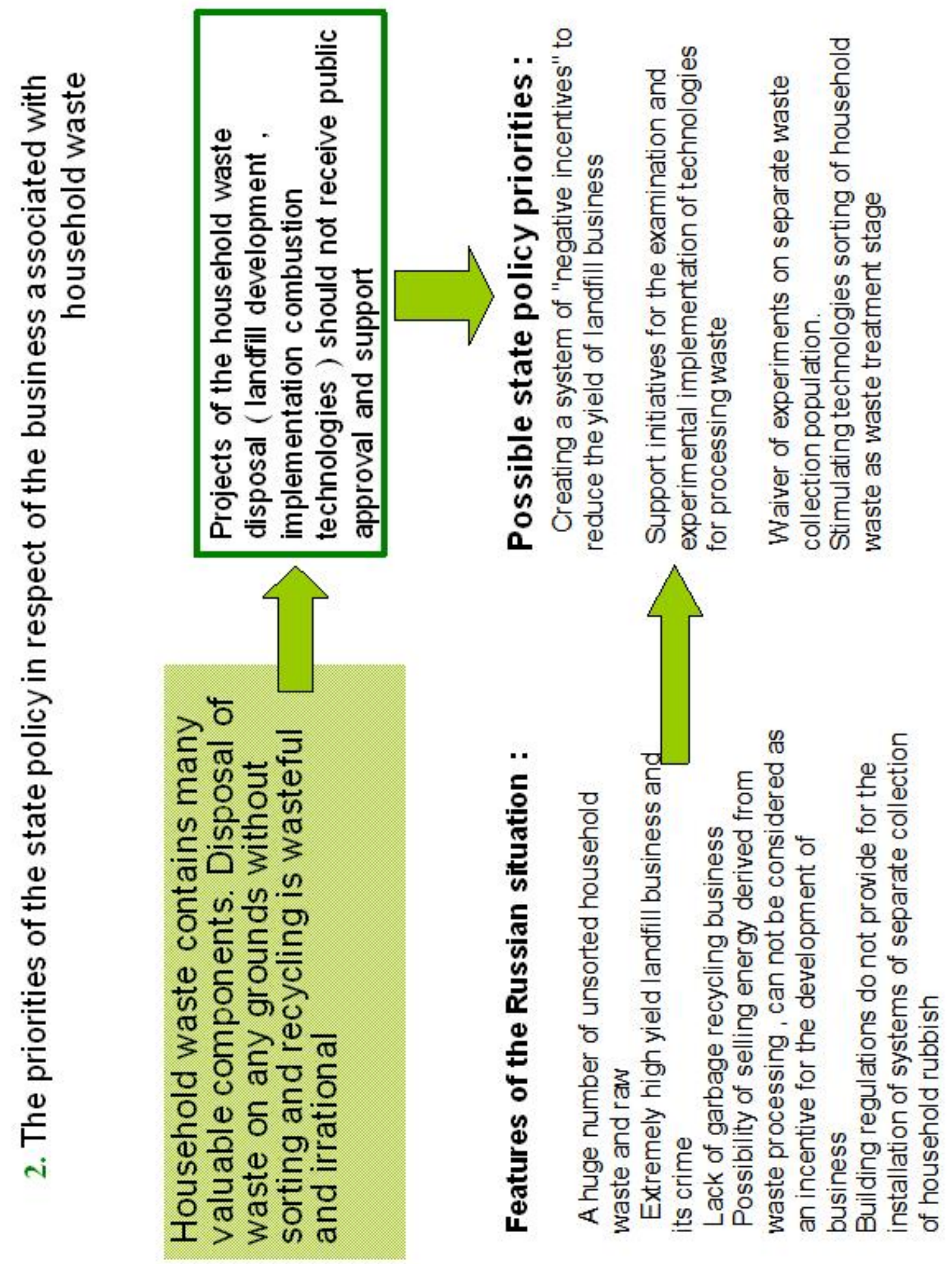




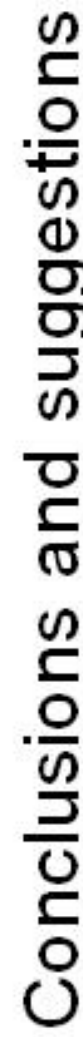

능

을 (1)

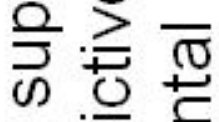

(1)

ज)

苑市

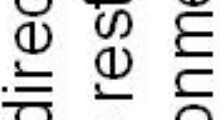

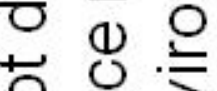

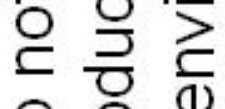

○

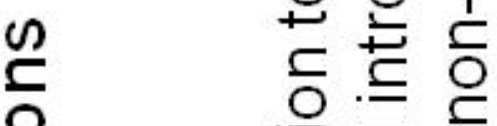

드드

(1)

艺 Ð

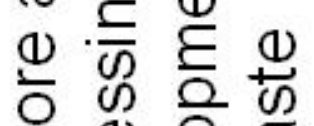

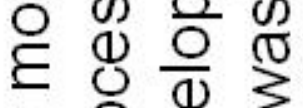

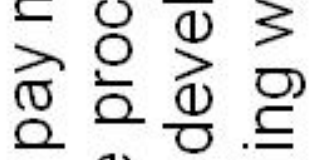

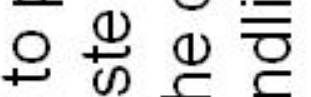

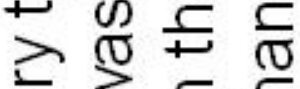

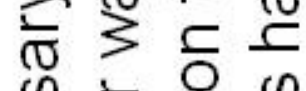

U

(4)

(1)

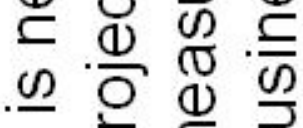

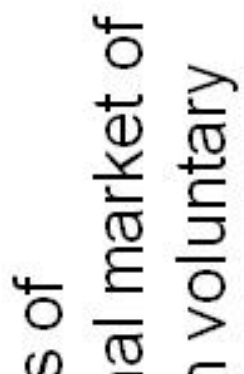

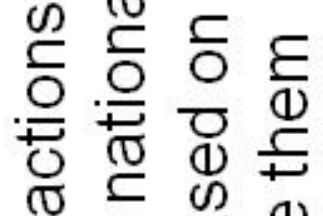

(ে ᄃ

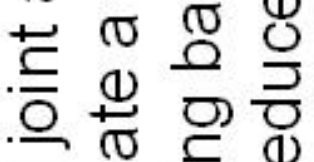

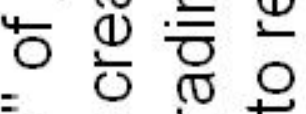

$=\frac{0}{2}+\frac{\pi}{2}+$

हั थ

ரே

$=$ 을 흘 ह

드릉

$\frac{0}{0} \frac{\pi}{0} \frac{0}{0}$

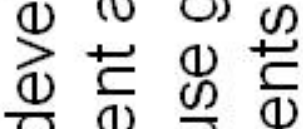

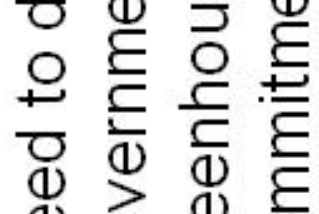

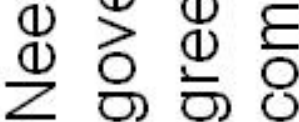




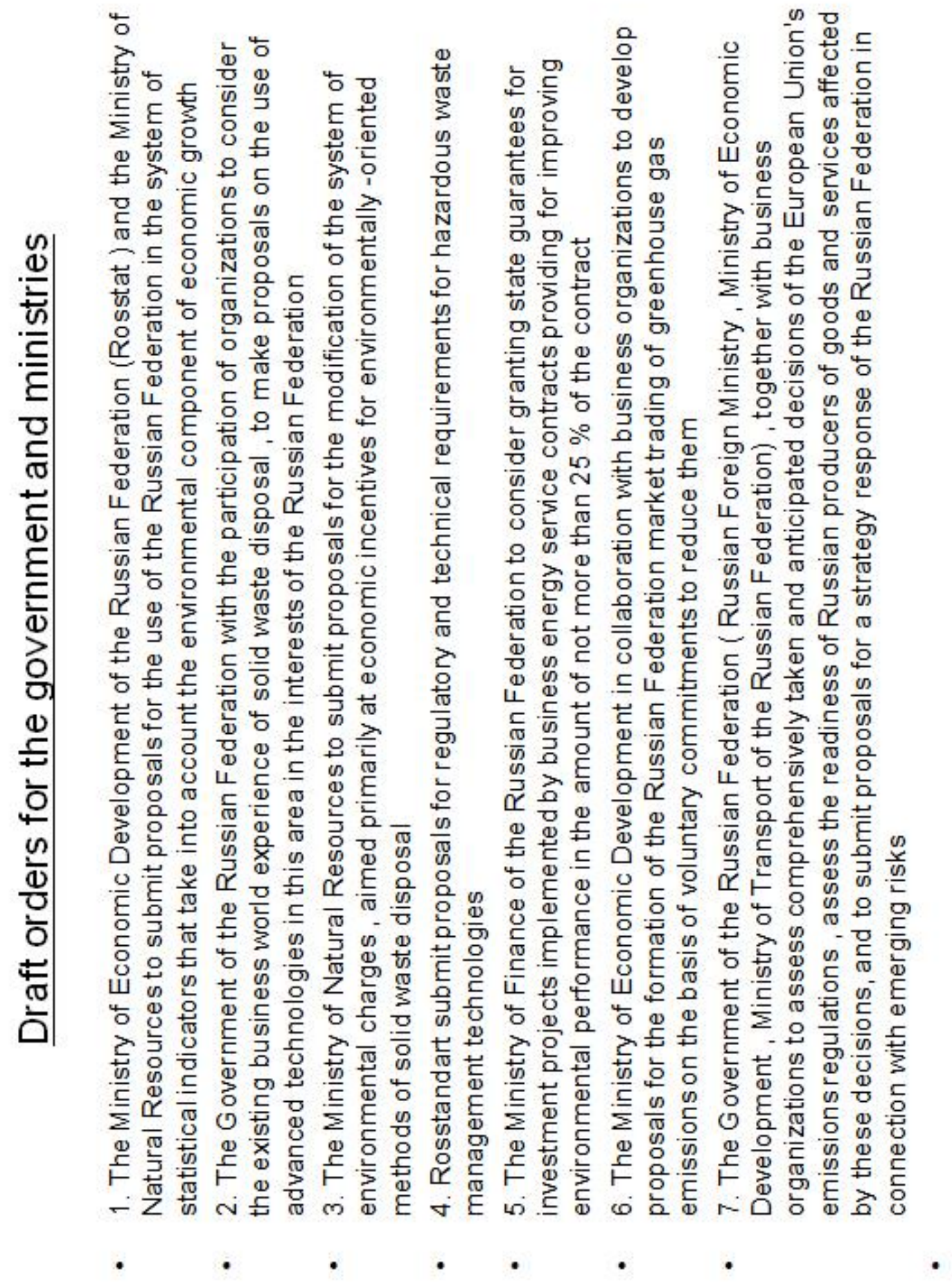


The investment program of development of waste management allows the investor to obtain information about the objects of investment and increase investment in the municipality .

An important element in attracting investors scope of treatment of municipal solid waste is to create conditions for investment attractiveness this sphere .

Evaluation of investment attractiveness of the sphere

Solid waste must consider each investment project, which is a condition for implementing the harmonization of interests and goals of the parties involved in this process.

The most effective tool to improve investment attractiveness is strategic planning, which should provide the flexibility and adaptability to future changes in the composition and the amount of solid waste and the availability of advanced technologies collection, removal and disposal. Strategic planning for solid waste management should be focused on the following important tasks : lower education level of waste and re-use ; security necessary capacities for the entire process chain of waste.

\section{CONCLUSION}

As a result of operation has been established, that:

1. It is necessary to pay more attention to not direct support projects for waste processing and introduce restrictive measures on the development of nonenvironmental businesses handling waste

2. Need to develop a "roadmap" of joint actions of government and business to create a national market of greenhouse gas emissions trading based on voluntary commitments by companies to reduce them

Also we presented our customer such draft orders for the government and ministries:

- 1. The Ministry of Economic Development of the Russian Federation (Rosstat ) and the Ministry of Natural Resources to submit proposals for the use of the Russian Federation in the system of statistical indicators that take into account the environmental component of economic growth

- 2. The Government of the Russian Federation with the participation of organizations to consider the existing business world experience of solid waste disposal , to make proposals on the use of advanced technologies in this area in the interests of the Russian Federation

- 3. The Ministry of Natural Resources to submit proposals for the modification of the system of environmental charges, aimed primarily at economic incentives for environmentally -oriented methods of solid waste disposal

- 4. Rosstandart submit proposals for regulatory and technical requirements for hazardous waste management technologies

- 5. The Ministry of Finance of the Russian Federation to consider granting state guarantees for investment projects implemented by business energy service contracts providing for improving environmental performance in the amount of not more than $25 \%$ of the contract

- 6. The Ministry of Economic Development in collaboration with business organizations to develop proposals for the formation of the Russian Federation market trading of greenhouse gas emissions on the basis of voluntary commitments to reduce them

- 7. The Government of the Russian Federation ( Russian Foreign Ministry, Ministry of Economic Development , Ministry of Transport of the Russian Federation), together with business organizations to assess comprehensively 
taken and anticipated decisions of the European Union's emissions regulations, assess the readiness of Russian producers of goods and services affected by these decisions, and to submit proposals for a strategy response of the Russian Federation in connection with emerging risks

Also work to improve the processing of municipal solid waste should go simultaneously with the improvement of the educational activities of the training of young engineers . 